\title{
Multidecadal variability in East African hydroclimate controlled by the Indian Ocean
}

\author{
Jessica E. Tierney ${ }^{1,2}$, Jason E. Smerdon ${ }^{2}$, Kevin J. Anchukaitis ${ }^{1,2}$ \& Richard Seager ${ }^{2}$
}

\begin{abstract}
The recent decades-long decline in East African rainfall ${ }^{1}$ suggests that multidecadal variability is an important component of the climate of this vulnerable region. Prior work based on analysing the instrumental record implicates both Indian $^{2}$ and Pacific ${ }^{1}$ ocean sea surface temperatures (SSTs) as possible drivers of East African multidecadal climate variability, but the short length of the instrumental record precludes a full elucidation of the underlying physical mechanisms. Here we show that on timescales beyond the decadal, the Indian Ocean drives East African rainfall variability by altering the local Walker circulation, whereas the influence of the Pacific Ocean is minimal. Our results, based on proxy indicators of relative moisture balance for the past millennium paired with long control simulations from coupled climate models, reveal that moist conditions in coastal East Africa are associated with cool SSTs (and related descending circulation) in the eastern Indian Ocean and ascending circulation over East Africa. The most prominent event identified in the proxy record-a coastal pluvial from 1680 to 1765 -occurred when IndoPacific warm pool SSTs reached their minimum values of the past millennium. Taken together, the proxy and model evidence suggests that Indian Ocean SSTs are the primary influence on East African rainfall over multidecadal and perhaps longer timescales.
\end{abstract}

The 2010-2011 drought in the Horn of Africa, by some measures the worst drought in 60 years $^{3}$, is a reminder that rainfall in this politically and socioeconomically vulnerable region can fluctuate dramatically. Prevailing La Niña conditions in the tropical Pacific were partly to blame; East African rainfall is teleconnected to the El Niño/Southern Oscillation ${ }^{4,5}$ (ENSO), and the Horn of Africa experiences droughts during La Niña events and pluvials during El Niño events. However, it is debated whether the failure of the 'long rains' (the rainy season of March, April and May) in 2011 - which exacerbated the drought-is related to decadal variability in the Indo-Pacific region ${ }^{1}$ or anthropogenic forcing ${ }^{1,2,6}$. It is critical for us to understand the character and mechanisms that drive decadal to centennial shifts in East African rainfall if we are to evaluate future regional projections of drought frequency and food security, but the short length of the instrumental record fundamentally limits our ability to understand variability on these timescales using observational data alone.

Palaeoclimate records in East Africa from the past millennium have the potential to extend the instrumental record and reveal mechanisms driving low-frequency climate variability. At present, annually resolved, absolutely dated terrestrial archives such as tree rings are sparse or underdeveloped in the region, but numerous lake basins in East Africa provide sedimentary archives with sufficient accumulation rates to resolve past-millennium climate ${ }^{7}$. Lake archives nevertheless have a fundamental limitation: they are not absolutely dated and, if constrained by radiocarbon $\left({ }^{14} \mathrm{C}\right)$ dating, can have a relatively large $(\sim 50-100-y r)$ temporal uncertainty due to compounded analytical and calibration errors. This uncertainty can make the identification of shared trends between different site archives challenging, especially within the time frame of the past millennium.

Here we synthesize lacustrine hydroclimatic proxy records from East Africa using a Monte Carlo empirical orthogonal function (MCEOF) approach ${ }^{8}$ to develop a spatiotemporal view of regional water balance during the past millennium that accounts for time uncertainty. We use proxy data from seven different lake basins (Fig. 1a; see Methods Summary for proxy selection criteria) that include charcoal, run-off indicators, lake level reconstructions and leaf wax hydrogen isotopes. The leading MCEOF of the proxy data explains $32 \pm 6 \%(2 \sigma)$ of the variance in the data and describes the primary regional mode of hydroclimatic variance during the past $\sim 700$ years (Fig. 1b). For sites that load positively on MCEOF1, the mode describes a pattern of late-medieval drought (1300 to 1400) followed by a gradual transition towards wetter conditions, culminating in peak pluvial conditions from about 1700 to 1750 , and a subsequent abrupt transition back towards drier conditions that persist until modern times (1950; Fig. 1b). Sites that load negatively on MCEOF1 show the opposite pattern and are dry during the eighteenth-century pluvial.

Some of the major features of MCEOF1, such as the medieval drought and the eighteenth-century pluvial, have been discussed and identified in previous site-specific studies ${ }^{9,10}$ and are also evident in some of the individual proxy data time series (Fig. 1a). Our analysis, however, identifies the spatial patterns of these features as well as their associated uncertainties. The spatial loading patterns of MCEOF1 clearly indicate that the sites closer to the eastern coastal/Horn of Africa region vary in antiphase with the interior Rift Valley sites (Fig. 1c). Although EOF analysis imposes a constraint of orthogonality that can complicate the interpretation of loading patterns in a climatic sense $^{11}$, this Horn-Rift dichotomy is consistent with convergence anomalies that occur in East Africa in response to altered Indian Ocean SST gradients ${ }^{12}$, and also approximates the spatial pattern of the first EOF of 10-yr low-pass-filtered instrumental rainfall data in the region (Fig. 1 and Supplementary Information). These features suggest that the loading pattern in MCEOF1 represents a real and important aspect of climate variability in East Africa that has dominated hydroclimate during the past millennium on the multidecadal timescale.

To explore the possible climatic mechanisms driving this variability, we analyse the relationship between annual precipitation in easternmost Africa-the coastal area that loads positively on MCEOF1-and SSTs in millennium-long control simulations conducted with fully coupled, atmosphere-ocean general circulation models (AOGCMs). These simulations provide sufficient degrees of freedom to investigate unforced, decadal to centennial climate variability, something that cannot be achieved with instrumental data or model simulations spanning only a few centuries. We use the 1,300- and 3,000-yr control runs from the US National Center for Atmospheric Research (NCAR) CCSM $4{ }^{13}$ AOGCM and the Geophysical Fluid Dynamics Laboratory (GFDL) CM2.1 ${ }^{14,15}$ AOGCM, respectively. Both models correctly simulate the ENSO-driven teleconnection between tropical Indo-Pacific SSTs and East African rainfall apparent in the instrumental record, although the correlation is stronger in the former than in the latter (Supplementary Fig. 3). To isolate low-frequency relationships, we apply a 50-yr low-pass filter to both the SST and the precipitation field, in line with the highest frequency recovered in MCEOF1 (Supplementary Fig. 4), and calculate the field correlations (Fig. 2). We find that although the central and eastern Pacific influence on East African rainfall is strong in the annual fields, it disappears on

${ }^{1}$ Woods Hole Oceanographic Institution, Woods Hole, Massachusetts 02543, USA. ${ }^{2}$ Lamont-Doherty Earth Observatory of Columbia University, Palisades, New York 10964, USA. 

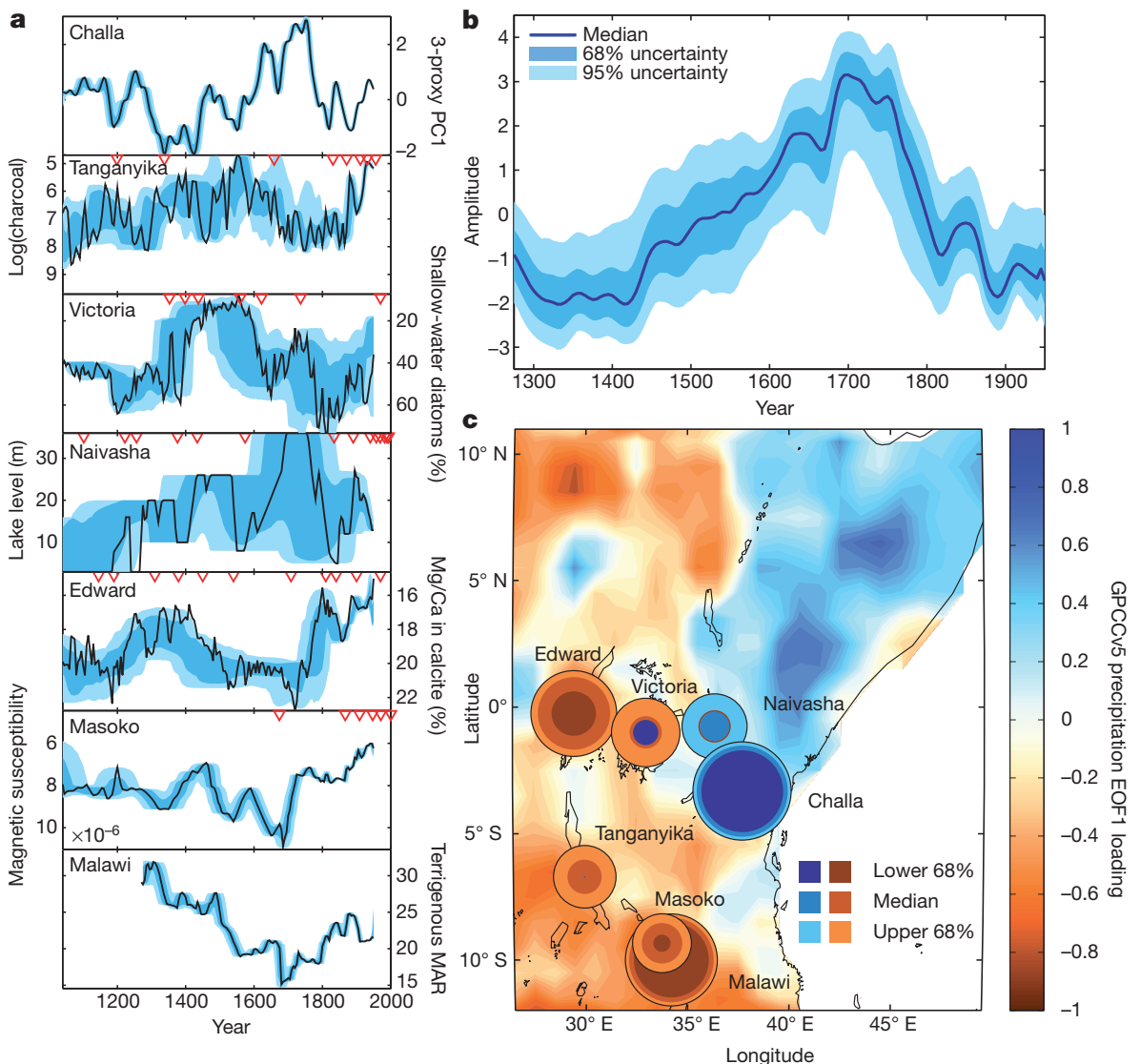

Figure $1 \mid$ Results of the MCEOF proxy synthesis. a, The seven proxy data time series used $^{9,10,20-28}$ (black lines indicate data on their published age models) and their associated time uncertainties (blue shading: light, 68\%; dark, 95\%). Red triangles denote chronological constraints (except for the varved Malawi and Challa data). Lake Challa's '3-proxy PC1' is the first principal component of three hydroclimate proxies

(Supplementary Information). Vertical axes are oriented such that wet conditions plot upwards. MAR, mass accumulation rate. $\mathbf{b}$, MCEOF1, shown with the median (solid blue line) and 68\% and 95\% two-tailed uncertainty bounds (blue shadings) empirically determined by 10,000 simulations. c, Proxy loadings on MCEOF1 (coloured circles), superimposed on the loading pattern (background colours) of the first EOF of the 10-yr low-passfiltered instrumental precipitation field $\left(\mathrm{GPCCv} 5^{29}\right)$. Circle diameter represents the loading value; circle colour represents the lower $68 \%$ bound (inner circle), median (middle circle) and upper $68 \%$ bound (outer circle). decadal and longer timescales (Fig. 2 and Supplementary Fig. 5). The only significant correlations that remain in the 50-yr low-pass-filtered field represent the association of wet conditions with warm SSTs in the western Indian Ocean and cool SSTs in the eastern Indian Ocean and western Pacific warm pool (Fig. 2).

Changes in model atmospheric vertical velocity are consistent with the changes in SSTs and provide insight into the mechanisms linking the surface ocean to rainfall variability. Figure 3 shows longitudeheight cross-sections of vertical velocity correlated with East African precipitation for the GFDL CM2.1 model. For the unfiltered data (Fig. 3a), wet conditions in East Africa are associated with a reorganization of the Walker circulation throughout the tropics, with anomalous rising motion over the central and eastern equatorial Pacific, descending motion over the far western Pacific and eastern Indian Ocean, and another cell of anomalous rising motion over the western Indian Ocean and East Africa. These correlations are typical of ENSO and are consistent with patterns of low-level wind anomalies driven by the SST gradients and associated atmospheric heating anomalies. In contrast, the low-pass-filtered vertical velocity correlations show that on multidecadal and longer timescales the tropical Pacific influence is considerably weaker (Fig. 3b). Instead, East African precipitation anomalies are controlled by a Walker circulation anomaly that is localized over the Indian Ocean, with wet conditions associated with ascending motion over East Africa and the western Indian Ocean and descending motion over the eastern Indian Ocean.

Collectively, these simulations imply that changes in Indian Ocean SSTs or the Indian Ocean SST gradient-and not the Pacific SST gradient-are the dominant influence on East African rainfall on multidecadal and longer timescales. Such changes in SSTs act to weaken or strengthen the Walker circulation in the Indian Ocean basin, thereby causing multidecadal pluvials or droughts, respectively. The Pacific influence on East African rainfall decays beyond the 10-yr timescale (Supplementary Fig. 5), probably reflecting the waning influence of interannual ENSO. Indeed, analysis of the power spectra of the simulated SSTs in the Pacific and Indian ocean basins, respectively, suggests that the central Pacific Ocean has relatively little spectral power in the multidecadal band whereas both the eastern and western Indian Ocean basins retain relatively more low-frequency power (Supplementary Fig. 6). These low-frequency oscillations are clearly capable of affecting the Walker circulation in the Indian Ocean basin independently of the Pacific, lending credence to, as well as extending, previous work suggesting that the Indian Ocean directly affects East African hydroclimate even in the interannual band ${ }^{12,16}$.

Changing Indian Ocean SST gradients may have dictated the evolution of East African hydroclimate during the past millennium. Independent proxy evidence of Indian Ocean SSTs would provide the most salient means of investigating this, but proxy SST records from the Indian Ocean basin over the past millennium are so far limited to coral archives that span at most the past few centuries. However, a recent sedimentary reconstruction from the Makassar strait provides a continuous SST record for the western Pacific warm pool over the past millennium ${ }^{17}$ and, given the known influence of the Indonesian Throughflow on southeastern Indian Ocean SSTs ${ }^{16}$, provides an indirect estimate of temperature variability in the easternmost portion of the Indian Ocean basin. This sedimentary reconstruction illustrates a remarkable similarity between the temporal evolution of Makassar SSTs and East African climate, with the coldest SSTs of the past millennium coeval with the coastal pluvial evident in MCEOF1 (Fig. 4). These palaeoclimate data support the mechanistic link between eastern Indian Ocean SSTs and East African rainfall seen in the AOGCM control runs, wherein cool SSTs in the eastern Indian Ocean are associated with wet conditions along the East African coast.

Determination of the role of western Indian Ocean SSTs, which are thought to be critical in terms of promoting local convergence anomalies on the interannual basis ${ }^{12}$, awaits long and continuous proxy SST data from the western Indian Ocean. However, it is dynamically consistent with our AOGCM results that cooler conditions in the western Pacific warm pool during the late seventeenth century and 
a
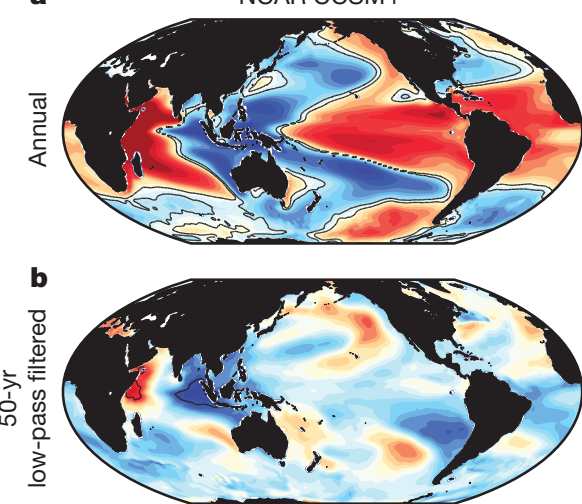

GFDL CM2.1
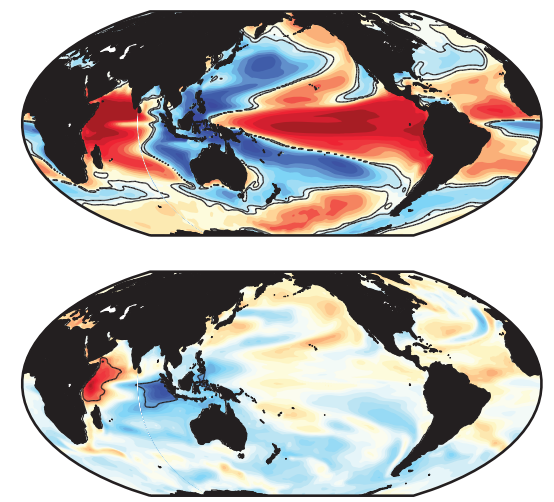

$-0.5$

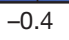

$-0.3$

Correlation coefficient, $r$

Figure 2 | Field correlations between simulated East African precipitation and SSTs. East African precipitation was averaged over the area spanned by $5^{\circ} \mathrm{S}-7^{\circ} \mathrm{N}$ and $36^{\circ}-46^{\circ} \mathrm{E}$, and then correlated with SSTs from long control simulations conducted with the NCAR CCSM4 AOGCM and the GFDL

the early eighteenth century helped reduced the east-west gradient in Indian Ocean SSTs, weakened the Walker circulation and promoted pluvial conditions in coastal East Africa and drought in the interior Rift
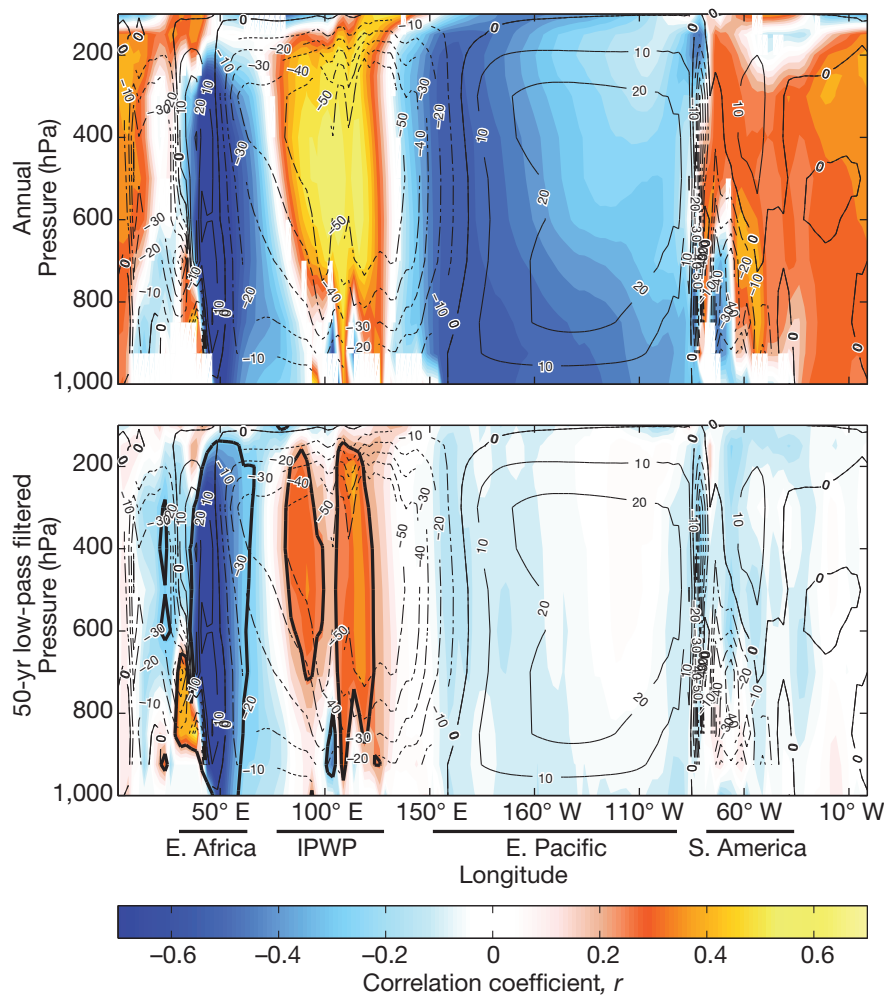

Figure 3 Field correlations between simulated East African precipitation and vertical velocity. 1Data are from the GFDL CM2.1 simulation.

Precipitation was averaged as in Fig. 2 and then correlated with vertical velocity $\left(\omega\right.$; positive values indicate descending motion; averaged over the $5^{\circ} \mathrm{S}-5^{\circ} \mathrm{N}$ latitude band) across the atmospheric pressure field. a, Annual field, showing only values for which a null hypothesis of no correlation can be rejected at the $5 \%$ level. b, 50-yr low-pass-filtered field. Heavy black contours demarcate regions in which a null hypothesis of no correlation can be rejected at the 5\% level. Light contours represent mean-annual simulated $\omega$ (hectopascals per day), indicating the locations of the ascending and descending branches of the Walker circulation. IPWP, Indo-Pacific warm pool.
CM2.1 AOGCM, respectively. a, Annual correlations; b, 50-yr low-pass-filtered correlations. Black contour lines demarcate regions in which a null hypothesis of no correlation can be rejected at the $5 \%$ level. $r$, Pearson correlation coefficient.

Valley. As the AOGCM simulations demonstrate, such multidecadal modulations of SSTs and East African climate can occur as part of natural, unforced climate variability, leaving open the possibility that the pluvial event in coastal Africa was at least in part a result of internal variability. However, the pluvial event and the cool conditions in the warm pool do occur during one of the coldest intervals of the Northern Hemisphere Little Ice $\mathrm{Age}^{18}$ and thus may be part of a global climate reorganization in response to radiative forcing.

This work presents an analysis of the spatial and temporal character of East African hydroclimate on decadal to centennial timescales, based on both palaeoclimate data and climate model simulations. In contrast to the dominant impact of ENSO on interannual rainfall variability, variations in the SST gradient across the Indian Ocean-which alter the Walker circulation-seem to be the principal control on hydroclimate in East Africa on multidecadal timescales. Whereas previous interpretations of palaeoclimate data from East Africa typically invoked ENSO or ENSOlike controls on East African precipitation ${ }^{10}$, our analysis suggests that palaeoclimate data that preferentially or exclusively record multidecadal or longer climate variability may be better understood in the context of the Indian Ocean, which has its own agency at lower frequencies.

The modelling simulations demonstrate that multidecadal oscillations in Indian Ocean SSTs can arise in response to internal climate

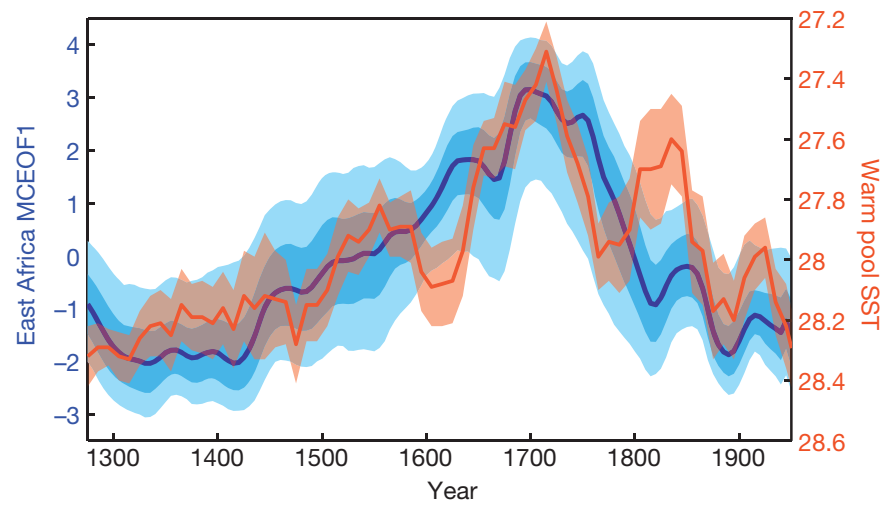

Figure $4 \mid$ Comparison between East Africa MCEOF1 (blue) and an SST reconstruction from the Makassar strait in the western Pacific warm pool (orange $)^{17}$. The right-hand axis is flipped such that cooler conditions plot upwards. Shading on MCEOF1 indicates the 68\% (dark) and 95\% (light) twotailed uncertainty bounds, as in Fig. 1. Shading on Makassar SSTs indicates the standard error on the binned proxy SST data as described in ref. 17. 
variability, but the palaeoclimate data hint at a forced response in that a cooler western Pacific warm pool and a coastal East African pluvial are associated with the Little Ice Age. Efforts to explain the recent decadal drought in the region and project future hydroclimatic change, whether forced or unforced, must acknowledge the existence of potent lowfrequency hydroclimate variability related to the Indian Ocean that is not detectable from the instrumental record alone. Present climate models predict that East Africa will get wetter as a consequence of increasing concentrations of greenhouse gases ${ }^{19}$, but the region has in fact gotten drier in recent decades ${ }^{1}$. This discrepancy could be explained either if a naturally occurring dry period, possibly of the type identified here, is obscuring a radiatively forced wetting trend or if the model projections are incorrect. More reliable projections of hydroclimate in this vulnerable region will require a better understanding of regional hydroclimate variability on decadal and longer timescales, how the regional climate responds to radiative forcings and how these two factors will combine to determine the future hydroclimate of East Africa.

\section{METHODS SUMMARY}

Seven palaeoclimate records of relative water balance from the East African region were included in the MCEOF synthesis, on the basis of the following criteria: the proxy primarily reflects hydroclimate; the proxy was measured at a time interval of 50 years or less; the age model is based on at least seven age-depth tie-points; there is at least one proxy data point representative of modern (post-1950) conditions; and the archive has a well-constrained stratigraphy free of reworking, large turbidites and sedimentary hiatuses. The MCEOF method, which is fully described in ref. 8, was applied to the data with the number of simulations set to 10,000 (ref. 8). Palaeoclimate data and age constraints were treated as described in ref. 8 with the exception of data from Lake Challa, in which case the first principal component of the three available hydroclimate proxy time series was used (Supplementary Information).

The GFDL CM2.1 model's ${ }^{14}$ pre-industrial control simulation spans 3,000 years and uses an atmospheric resolution of $2^{\circ}$ latitude by $2^{\circ}$ longitude by 24 vertical levels and an oceanic resolution of $1^{\circ}$ latitude (increasing to $1 / 3^{\circ}$ near the equator) by $1^{\circ}$ longitude by 50 vertical levels. The NCAR CCSM 4 model's ${ }^{13}$ pre-industrial control simulation spans 1,300 years and uses an atmospheric resolution of $1^{\circ}$ latitude by $1^{\circ}$ longitude by 26 vertical layers and an oceanic resolution of $0.54^{\circ}$ latitude (increasing to $0.27^{\circ}$ near the equator) by $1.11^{\circ}$ longitude by 60 vertical levels. For model analyses, we averaged precipitation over the area spanned by $5^{\circ} \mathrm{S}-7^{\circ} \mathrm{N}$ and $36^{\circ}-46^{\circ} \mathrm{E}$. Annual precipitation, SST and vertical velocity (for the GFDL simulation) fields were filtered with an eight-point Butterworth filter before calculating the correlation coefficients of the low-pass-filtered fields in Figs 2 and 3. All annual fields were calculated from monthly means. For further details regarding the model analyses, see Supplementary Information.

Data from this paper is available from NOAA's World Data Center for Paleoclimatology (www.ncdc.noaa.gov/paleo).

Received 30 July; accepted 8 November 2012.

1. Lyon, B. \& DeWitt, D. A recent and abrupt decline in the East African long rains. Geophys. Res. Lett. 39, L02702 (2012).

2. Williams, A. \& Funk, C. A westward extension of the warm pool leads to a westward extension of the Walker circulation, drying eastern Africa. Clim. Dyn. 37, 2417-2435 (2011).

3. Famine Early Warning System Network. East Africa: past year one of the driest on record in the eastern Horn. http://www.fews.net/docs/Publications/FEWS NET EA_Historical drought context_061411pdf (2011).

4. Nicholson, S. \& Entekhabi, D. The quasi-periodic behavior of rainfall variability in Africa and its relationship to the Southern Oscillation. Meteorol. Atmos. Phys. 34, 311-348 (1986).

5. Ropelewski, C. \& Halpert, M. Global and regional scale precipitation patterns associated with the El Niño/Southern Oscillation. Mon. Weath. Rev. 115, 1606-1626 (1987)

6. Funk, C. etal. Warming of the Indian Ocean threatens eastern and southern African food security but could be mitigated by agricultural development. Proc. Natl Acad. Sci. USA 105, 11081-11086 (2008).

7. Verschuren, D. in Past Climate Variability Through Europe and Africa (eds Battarbee, R. W., Gasse, F. \& Stickley, C. E.) 219-256 (Springer, 2004).
8. Anchukaitis, K. J. \& Tierney, J. E. Identifying coherent spatiotemporal modes in time-uncertain proxy paleoclimate records. Clim. Dyn. advance online publication, http://dx.doi.org/10.1007/s00382-012-1483-0 (26 August 2012).

9. Verschuren, D., Laird, K. R. \& Cumming, B. F. Rainfall and drought in equatorial East Africa during the past 1,100 years. Nature 403, 410-414 (2000),

10. Russell, J. M. \& Johnson, T. C. Little Ice Age drought in equatorial Africa: Intertropical Convergence Zone migrations and El Niño-Southern Oscillation variability. Geology 35, 21-24 (2007).

11. Dommenget, D. \& Latif, M. A cautionary note on the interpretation of EOFs. J. Clim. $15,216-225$ (2002)

12. Ummenhofer, C. C., Gupta, A. S., England, M. H. \& Reason, C. J. C. Contributions of Indian Ocean sea surface temperatures to enhanced East African rainfall. J. Clim. 22, 993-1013 (2009)

13. Gent, P. et al. The community climate system model version 4. J. Clim. 24, 4973-4991 (2011)

14. Delworth, T. et al. GFDL's CM2 global coupled climate models. Part I: formulation and simulation characteristics. J. Clim. 19, 643-674 (2006).

15. Wittenberg, A. Are historical records sufficient to constrain ENSO simulations? Geophys. Res. Lett. 36, L12702 (2009).

16. Black, E., Slingo, J. \& Sperber, K. R. An observational study of the relationship between excessively strong short rains in coastal East Africa and Indian Ocean SST. Mon. Weath. Rev. 131, 74-94 (2003).

17. Oppo, D. W., Rosenthal, Y. \& Linsley, B. K. 2,000-year-long temperature and hydrology reconstructions from the Indo-Pacific warm pool. Nature 460, 1113-1116 (2009).

18. Jansen, E. J.etal. in Climate Change 2007: The Physical Science Basis (eds Solomon, S. et al.) 433-498 (Cambridge Univ. Press, 2007).

19. Christensen, J. H. et al. in Climate Change 2007: The Physical Science Basis (eds Solomon, S. et al.) 847-940 (Cambridge Univ. Press, 2007).

20. Verschuren, D. etal. Half-precessional dynamics of monsoon rainfall near the East African equator. Nature 462, 637-641 (2009).

21. Tierney, J. E., Russell, J. M., Sinninghe Damsté, J. S., Huang, Y. \& Verschuren, D. Late Quaternary behavior of the East African monsoon and the importance of the Congo Air Boundary. Quat. Sci. Rev. 30, 798-807 (2011).

22. Wolff, C. et al. Reduced interannual rainfall variability in East Africa during the last ice age. Science 333, 743-747 (2011)

23. Stager, J. C., Ryves, D. B., Cumming, B. F., Meeker, L. D. \& Beer, J. Solar variability and the levels of Lake Victoria, East Africa, during the last millenium. J. Paleolimnol. 33, 243-251 (2005).

24. Tierney, J. et al. Late-twentieth-century warming in Lake Tanganyika unprecedented since AD 500. Nature Geosci. 3, 422-425 (2010).

25. Garcin, Y. et al. Centennial to millennial changes in maar-lake deposition during the last 45,000 years in tropical Southern Africa (Lake Masoko, Tanzania). Palaeogeogr. Palaeoclimatol. Palaeoecol. 239, 334-354 (2006).

26. Garcin, Y. et al. Solar and anthropogenic imprints on Lake Masoko (southern Tanzania) during the last 500 years. J. Paleolimnol. 37, 475-490 (2007).

27. Brown, E. T. \& Johnson, T. C. Coherence between tropical East African and South American records of the Little Ice Age. Geochem. Geophys. Geosyst. 6, Q12005 (2005).

28. Johnson, T. \& McCave, I. Transport mechanism and paleoclimatic significance of terrigenous silt deposited in varved sediments of an African rift lake. Limnol. Oceanogr. 53, 1622-1632 (2008).

29. Rudolf, B., Becker, A., Schneider, U., Meyer-Christoffer, A. \& Ziese, M. GPCC status report, December 2011. http://www.dwd.de/bvbw/generator/DWDWWW/ Content/Oeffentlichkeit/KU/KU4/KU42/en/Reports_Publications/GPCC status_report_2010,templateld=raw,property=publicationFile.pdf/GPCC status_report_2010.pdf (2011).

Supplementary Information is available in the online version of the paper.

Acknowledgements J.E.T. acknowledges the US NOAA Climate and Global Change Postdoctoral Fellowship and NSF OCE-1203892 for support. J.E.S. and R.S. were supported by the NOAA award Global Decadal Hydroclimate Variability and Change (NA100AR431037). We thank the National Center for Atmospheric Research, who made the CCSM4 control simulation available through the US Earth System Grid (ESG) Center. Support for the ESG is provided by the Office of Science, US Department of Energy, with co-sponsorship from the US NSF. Thanks also to NOAA GFDL for providing the multimillennial control simulation output from the GFDL CM2.1 model, to N. Naik for her on-site support at LDEO and to J. Jungclaus of the Max Planck Institute for providing output from the MPI COSMOS control simulation. This is LDEO contribution number 7641.

Author Contributions J.E.T. designed the study and interpreted the palaeoclimate results. J.E.S. provided the climate modelling results. K.J.A. and J.E.T. designed and implemented the MCEOF method. J.E.S. and R.S. interpreted the dynamical implications of the climate model output. All authors collaborated on the synthesis of the proxy and model data and the writing of the manuscript.

Author Information Reprints and permissions information is available at www.nature.com/reprints. The authors declare no competing financial interests. Readers are welcome to comment on the online version of the paper. Correspondence and requests for materials should be addressed to J.E.T. (tierney@whoi.edu). 